phagocytosis was quantified using fluorimetry. Release of TNFo, CXCL8 and IL-6 was measured by ELISA. Expression of macrophage receptor with collagenous structure (MARCO) and tolllike receptors (TLRs) 2 and 4 was measured by flow cytometry.

Results Neither CSE nor any of the e-CVEs had any significant effect on cell viability. In addition, none of the exposures produced any significant effect on phagocytosis, though higher concentrations of CSE displayed a trend towards reduced phagocytosis.

CSE significantly reduced $\mathrm{TNF} \alpha$ release (by approximately $70 \% ; \mathrm{p}<0.05)$. Tobacco- and banoffee pie-flavoured e-CVEs also caused significant reductions in TNF $\alpha$ release (by 30-50\%; $\mathrm{p}<0.05$ ), while nicotine and the e-liquid vehicle had no effect. Minimal effects were observed on CXCL8 and IL-6 release (0$30 \%$ reduction; $p>0.05$ ) with CSE and e-CVEs. Expression of MARCO and TLR4 were unaffected by all cell treatments. TLR2 expression appeared to be slightly increased by e-CVEs, but was not statistically significant.

Conclusion Effects of e-CVEs on MDMs differed from those of CSE. E-liquid flavourings appeared to be responsible for changes in MDM function, while the e-liquid vehicle and nicotine solution had minimal effects. More research is needed to improve understanding of the biological effects of e-cigarette flavourings.

\section{S124 THE EFFECTIVENESS OF "IN-CLINIC" SMOKING CESSATION SUPPORT IN THE SETTING OF SECONDARY CARE RESPIRATORY OUTPATIENT SERVICES}

${ }^{1}$ I Valero-Sanchez, ${ }^{1} \mathrm{~S}$ Agrawal, ${ }^{2} \mathrm{~S}$ Brij, ${ }^{1} \mathrm{RA}$ Evans, ${ }^{1} \mathrm{NJ}$ Greening, ${ }^{3} \mathrm{M}$ Perry, ${ }^{1} \mathrm{~N}$ Toms, ${ }^{4} \mathrm{E}$ Wiggins, ${ }^{5} \mathrm{~J}$ Williams, ${ }^{1} \mathrm{MC}$ Steiner. ${ }^{1}$ University Hospitals of Leicester, Leicester, UK; ${ }^{2}$ Peterborough City Hospital, Peterborough, UK; ${ }^{3}$ Leicester City Council, Leicester, UK; ${ }^{4}$ Peterborough City Council, Peterborough, UK; ${ }^{5}$ Cambridge and Peterborough Foundation Trust, Peterborough, UK

\subsection{6/thoraxjnl-2016-209333.130}

Introduction and aims Although two thirds of smokers wish to quit, referral, uptake and engagement with smoking cessation (SC) services are frequently poor. In Leicester, uptake of smoking cessation referred from secondary care is approximately $20 \%$ with successful quit rate at four weeks of $10 \%$. Provision of immediate support through smoking cessation specialist advice provided at the point of clinical assessment in outpatients might enhance referral uptake and quit rates. We assessed the value of this "in-clinic" approach in specialist respiratory outpatient clinics in two secondary care centres.

Methods Provision of immediate smoking cessation advice was implemented in two outpatient clinic services providing specialist care for patients with complex, chronic obstructive pulmonary disease (COPD); an Acute General Hospital (Peterborough City Hospital, PCH) and a Tertiary Care Hospital (Glenfield Hospital, $\mathrm{GH})$. All current smokers were referred to an on-site smoking cessation specialist advisor by the physician, or clinic nurse, as part of their outpatient review on the same day of their clinic visit.

In the Glenfield service SC was provided by a smoking cessation specialist, using a harm reduction approach with a guided patient-led tailored programme and the possibility of direct supply treatment at the initial assessment.

In the PCH service, SC using psychosocial and/or pharmacological therapy was undertaken by a dedicated smoking cessation officer
Follow-up visits and telephone calls were arranged separately by the smoking service and data including demographics, treatment uptake and quit rates after 4 weeks were analysed.

Results A population of 122 smokers with a diagnosis of COPD were assessed for in-clinic SC over a period of twelve months in both centres.

Demographic details of both cohorts, outcomes of both SC strategies including treatment uptake and quit rates are disclosed in Table 1.

Conclusions Providing "in-clinic", expert smoking cessation advice results in favourable referral uptake and four week quit rates when compared with locally available data from paper based referral routes. Reinforcing physician delivered smoking cessation advice through immediate provision of proactive cessation support may be an effective means to enhance quit rates in secondary care.

\begin{tabular}{|c|c|c|}
\hline & $\begin{array}{l}\text { In-Clinic SC Approach at } \\
\text { Peterborough Hospital }\end{array}$ & $\begin{array}{l}\text { In-Clinic SC Approach at } \\
\text { Glenfield Hospital }\end{array}$ \\
\hline $\mathrm{N}$ patients referred & 65 & 57 \\
\hline $\begin{array}{l}\text { Age (years) (mean, } \\
\text { [SD]) }\end{array}$ & 61.3 [9] & $61.1[9]$ \\
\hline Gender & $53 \%$ Male & $53 \%$ Male \\
\hline Approach to SC & Conventional & Harm Reduction \\
\hline $\begin{array}{l}\text { Treatment Uptake }(\% \\
\text { of } \mathrm{N})\end{array}$ & $32(49 \%)$ & $29(50 \%)$ \\
\hline $\begin{array}{l}\text { SC managed after } 4 \\
\text { weeks (\% of } N)\end{array}$ & $29(44 \%)$ & $16(28 \%)$ \\
\hline
\end{tabular}

\section{S125 SMOKING CESSATION KNOWLEDGE, BELIEFS AND CURRENT PRACTICES AMONG UK CHILD HEALTH PROFESSIONALS}

${ }^{1}$ MJP Robertson, ${ }^{1} \mathrm{~A}$ Gupta, ${ }^{2} \mathrm{~J}$ Arumugam. 'Department of Paediatric Respiratory Medicine, King's College Hospital, London, UK; ' ${ }^{2}$ Department of Paediatrics, Basildon and Thurrock University Hospitals, Basildon, UK

\subsection{6/thoraxjnl-2016-209333.131}

Introduction and objectives Two million children in the UK are regularly exposed to second-hand smoke (SHS) in the home and many more are exposed in other settings. The consequences of this are well recognised and include higher incidences of: numerous acute illnesses; hospital admissions; school absences and increased smoking rates in later life. Together these result in significant costs to the NHS and wider economy.

Barriers to improved practice have been reported in other professional groups in the UK and in Child Health Doctors and Nurses in other countries. We could find no previously published data from the UK on this topic with which to inform and improve our own staff training and support.

Methods An electronic questionnaire was developed, covering beliefs, knowledge and current practice. The survey was distributed through professional groups, training and healthcare delivery organisations.

Results 140 responses were received, from Consultants (22\%), trainee Paediatricians (32\%), Nurses (34\%) and others (11\%), including Physiotherapists, Pharmacists, Healthcare Assistants and Play Therapists. Respondents came from 19/21 UK regions. 